\title{
La simpatía smithiana como vía para reducir la aporofobia derivada de la corrupción
}

\author{
PABLO AYALA ENRÍQUEZ* \\ Tecnológico de Monterrey (México) \\ pabloayala@tec.mx
}

\begin{abstract}
Resumen
Los escándalos de corrupción dados a conocer durante los últimos tres años en Latinoamérica, además de reflejar el modo en que la corrupción mueve los engranajes de las instituciones y organizaciones empresariales, pueden considerarse como uno de los principales detonantes de la aporofobia (rechazo, odio al pobre) y ceguera moral (incapacidad para identificar la condición de vulnerabilidad de los demás) que aqueja a nuestras sociedades. Teniendo en consideración los resortes que activan ambos fenómenos, el presente artículo explora las posibilidades que tiene la simpatía smithiana para desactivarlos, así como el aporte social de ésta en la lucha contra la corrupción que cualquier país pudiera emprender.
\end{abstract}

Palabras clave: Corrupción, aporofobia, ceguera moral, simpatía, pobreza, espectador imparcial.

\section{The smithian sympathy as a way to reduce the aporophobia derived from corruption}

\begin{abstract}
The corruption scandals unveiled during the last three years in Latin America, in addition to reflecting the way in which corruption moves the gears of the institutions and business organizations, can be considered as one of the main triggers of the aporophobia (rejection, hatred of the poor) and moral blindness (inability to identify the condition of vulnerability of others) that afflicts our societies. Considering the springs that activate both phenomena, this article explores the possibilities that smithian sympathy has to deactivate them, as well as its social contribution in the fight against corruption that any country could undertake.
\end{abstract}

Key words: Corruption, aporophobia, moral blindness, sympathy, poverty, impartial spectator.

\footnotetext{
* Doctor en Ética y Democracia por la Universidad de Valencia, España. Actualmente es Decano Asociado de Formación Ética y Ciudadana. Entre sus publicaciones destacan: “Es posible construir una ciudadanía fuerte en nuestra democracia liberal?" (2011); "Agenda para una revolución ciudadana en México" (2010); “Podemos hablar de una educación para la simpatía solidaria?” (2009); "La pobreza en Latinoamérica. Un análisis desde la hermenéutica crítica" (2009).
} 


\section{INTRODUCCIÓN}

"Los Panamá Papers", "Lava Jato", "Los cuadernos"3 y "La estafa maestra", son tan solo cuatro ejemplos que ilustran el modo en que la corrupción aceita los engranajes de la maquinaria institucional, pone en riesgo la gobernabilidad, impacta negativamente las finanzas y fondos de las arcas públicas, vulnera derechos, provoca inestabilidad social y aumenta las brechas de pobreza en buena parte de los países latinoamericanos.

Y aunque ciertamente el fenómeno de la corrupción no es exclusivo de nuestro continente, "desaparecer" recursos públicos en países donde millones de personas viven en condiciones de precariedad, más que un condenable desfalco, deja entrever la creciente "aporofobia" que aqueja a nuestras sociedades, es decir, el "rechazo, aversión, temor y desprecio hacia el pobre, hacia el desamparado [a ese] que, al menos en apariencia, no puede devolver nada bueno a cambio" (Cortina, 2017: 14).

La aporofobia aludida por Adela Cortina, debido a su trasfondo filosófico, se encuentra muy próxima a la idea de "insensibilidad", de "ceguera

1 La investigación realizada por el periodista alemán Bastian Obermayer y el Consorcio Internacional de Periodistas de Investigación, que detonó el caso de los "Panama Papers", tras el análisis de más de 11.5 millones de documentos que contenían información confidencial de 214, 488 empresas "Offshore", descubrió una trama de corrupción en la aparecieron nombres de dirigentes de Estado, políticos, empresarios, deportistas, intelectuales, artistas y filántropos (Ayala, 2016).

2 En marzo de 2014, la policía federal brasileña a través de la operación "Lava Jato" (lavadero de coches) atrapó a una banda de 30 personas que se dedicaban al lavado de dinero, la evasión de divisas, el desvío de recursos públicos, al contrabando de piedras preciosas y al narcotráfico. A la banda se le acusó de haber lavado alrededor de 4,350 millones de dólares. En diciembre de 2014, un mes antes de ser reelecta, Dilma Rousseff apareció en la lista de las personas que tendrían que presentarse a declarar por haber sido señalada como una de las implicadas en la trama. A principios de marzo de 2015 el fiscal general, Rodrigo Janot, pidió que se abriera la investigación en contra de 54 personas, y tres días después la Suprema Corte autorizó la investigación a 49 de éstas, de las cuales 22 eran diputados y 12 senadores. Los que se llevaron los reflectores fueron el presidente del senado y el congreso, y el presidente de la cámara de diputados.

3 La investigación periodística realizada por Diego Cabot, conocida como "los cuadernos" destapó una trama de corrupción argentina orquestada desde la casa y oficina de los expresidentes Kirchner, donde se vieron involucrados funcionarios públicos de alto nivel y empresas contratistas del Estado desviando millones de dólares de las arcas públicas (Cabot, 2018).

4 "La estafa maestra" se articuló gracias a un sistema de triangulación entre algunas secretarías de estado, universidades y empresas mexicanas, con el que se desvió un monto "de 2 mil 224 millones, que debían destinarse a ampliar la cobertura de programas sociales, [ofrecer] mejores servicios en las zonas más rezagadas del país para combatir la pobreza extrema" (Animal Político, 2018). 
moral" que Zygmunt Bauman y Leonidas Donskis explican de la siguiente manera:

... tipo de comportamiento cruel, inhumano y despiadado, o bien una postura ecuánime e indiferente adoptada y manifestada hacia las pruebas y tribulaciones de otras personas (el tipo de postura resumida en el gesto de 'lavarse las manos', de Poncio Pilato). Utilizamos 'insensibilidad' como una metáfora; su ubicación primordial reside en la esfera de los fenómenos anatómicos y fisiológicos de los que deriva; su significado primordial es la disfunción de algunos órganos de los sentidos, ya sean ópticos, auditivos, olfativos o táctiles, que derivan en una incapacidad para percibir estímulos que bajo condiciones 'normales' evocarían imágenes, sonidos u otras impresiones (Bauman \& Donskis, 2015: 23).

La insensibilidad moral referida se da en personas "terriblemente normales y cuerdas" (Bauman \& Donkins, 2015: 14), como lo son los actores de las tramas de corrupción referidas líneas arriba, y que, pareciera, son incapaces de compadecerse ante el infortunio o la desgracia ajena, sentimiento moral que, como decía Adam Smith, hasta el hombre más egoísta podría ser capaz de sentir (Smith, 2004a).

Dar respuesta a la pregunta qué empujó a esas personas a perpetrar tales tramas de corrupción, aun y cuando eran conscientes de que éstas generarian daños sociales irreparables, precisa ir más allá del análisis del quebrantamiento del marco legal y adentrarnos en las motivaciones morales que los condujeron a actuar de espaldas a principios éticos que en algún momento dado defendieron públicamente ${ }^{5}$.

Movidos por dicha inquietud, los siguientes apartados inician con un breve recorrido por los entretelones morales de la noción, sus causas y efectos, para luego identificar la potencialidad que tiene la simpatía smithiana como contrapeso a la aporofobia y ceguera moral descritas líneas arriba. El último apartado, en un tono más próximo a la propuesta, expone el aporte social de dicha noción en la lucha contra la corrupción.

\section{LA CORRUPCIÓN Y SU ENTRAMADO MORAL}

La corrupción ha estado presente a lo largo de la historia de la humanidad (Holmes, 2015), convirtiéndose en "un tema de interés nacional e internacional, pues ningún país es ajeno. Se puede encontrar en las normas éticas y religiosas más antiguas y profusamente en las Sagradas Escrituras.

5 Geofferey Klempner señala que la dificultad al momento de actuar éticamente surge de la naturaleza de la situación que estamos encarando, más que de la pérdida de la sabiduría o del conocimiento ético (Klempner, 2017). 
[...] Desviar las potestades públicas en beneficio de los intereses particulares es uno de los fenómenos más antiguos de la naturaleza humana, tan antiguo como la propia existencia del poder" (Myers \& Rouzaud, 2016: 137). Y justamente, porque hay muchas variedades de comportamientos corruptos, una multitud de factores que contribuyen a la corrupción, que son tantas "las explicaciones ofrecidas, y la dificultad para clasificarlas de una manera sistemática" (De Graaf, 2007: 42).

La discusión sobre qué es la corrupción, al igual que sucede con la función que tiene la ética en nuestras vidas, aún está muy lejos del consenso, sin que ello signifique, como apunta Gerald Caiden, que "la confusión invalide ciertas generalizaciones universales" (Caiden, 2001: 78). "Ocurre lo mismo que a la estatura, al peso o al color, que no se puede vivir sin ellos. Todos los seres humanos son más o menos altos o bajos, todos son morenos, rubios o pelirrojos, todos pesan más o menos, pero ninguno carece de estatura volumen o color. Igual sucede con la ética, que una persona puede ser más moral o menos según determinados códigos, pero todas tienen alguna estatura moral" (Cortina, 2013: 11). Lo mismo podemos decir de la corrupción: "el grado de corrupción varía ampliamente entre individuos, agencias públicas, culturas administrativas y regiones geográficas" (Caiden, 2001: 26).

No somos absolutamente corruptos o totalmente íntegros; hay grados, matices, variaciones, como las hay respecto al significado del acto corrupto. Al igual que las normas morales, las que definen la acción deshonesta siempre están asociadas al momento histórico y la cultura, porque, como dijera Friedrich Nietzsche, "en el terreno de la moral todo se modifica y cambia, todo es incierto y está en constante fluctuación" (Nietzsche, 2015: 11). Las normas morales se configuran, aceptan y modifican con el paso del tiempo, sobre todo en una sociedad democrática y liberal, donde es posible que "cada quien defienda y persiga sus ideales de felicidad. Ideales que, a mi modo de ver, configuran unos 'máximos éticos' en los que no tienen por qué estar de acuerdo todos los ciudadanos para convivir -no sólo para coexistir-, desde el mutuo respeto y aprecio" (Cortina, 2000: 49).

Vista así, la moral, como la dibuja Anthony Appiah, es un espejo hecho añicos: "en todos lados hay partes de la verdad (junto con muchos errores), y la verdad entera no está en ningún lado. La equivocación más grave es pensar que nuestro pequeño fragmento del espejo puede reflejar el todo. [...] A menudo podemos apreciar el atractivo de valores que no son exactamente los nuestros. Entonces, quizá no haya una verdad singular en lo que atañe a la moral. Así, no hay un espejo hecho añicos, hay muchos espejos, muchas verdades morales y lo máximo que podemos hacer es aceptar nuestras diferencias" (Appiah, 2007: 34-9). 
La discusión en torno a la corrupción comparte el mismo escenario descrito por Appiah. Hay miradas, convergencias, pero no definiciones únicas. Por ello, de manera preliminar podemos decir con Cardona, Ortiz y Vázquez, que la noción de corrupción se encuentra asociada a la:

... captura o cooptación estatal, tráfico de influencias, conflicto de intereses, negociaciones incompatibles, parcialidad, donación en campañas electorales, malversación de fondos, partidas presupuestarias secretas, fraudes, uso de información privilegiada, enriquecimiento ilícito, soborno, extorsión, arreglos, colusión privada, alteraciones fraudulentas del mercado, especulación financiera con fondos públicos, puerta giratoria, clientelismo, nepotismo, compra de votos, todas éstas son actividades que se relacionan con alguna idea de corrupción. Si bien cada una de ellas supone relaciones, actividades y consecuencias distintas, mantienen un aire de familia esencialmente normativo: hubo algo mal hecho que privatiza el poder público, hay una acción reprochable (Cardona, Ortiz \& Vázquez, 2018: 155).

Como se puede ver, la amplitud del escenario donde se despliega la corrupción es proporcional a las aristas de la discusión que trata de definirla. Leslie Holmes ilustra el problema a través de un par de ejemplos. La confusión terminológica existente, ha impedido a las Naciones Unidas generar un instrumento que sirva para combatir las distintas formas en que se presenta la corrupción en todo el mundo. Así mismo, Transparencia Internacional, referente a nivel internacional del combate a la corrupción, ha venido utilizando dos definiciones que no significan necesariamente lo mismo: "el abuso de un cargo público para obtener una ganancia privada" (Corruption Perceptions Index, 2018) y "el abuso del poder conferido para obtener una ganancia privada" (Transparencia Internacional). Como señala Holmes, la principal diferencia entre estas dos definiciones es que la primera requiere que un oficial del estado esté involucrado, y en la segunda se precisa de un comportamiento ruin por parte de los ejecutivos. En 2012, Transparencia Internacional dejó de difundir su noción de corrupción pública conforme lo había venido haciendo en el Índice de Percepción de la Corrupción, provocando con dicha decisión una considerable confusión (Holmes, 2015).

¿Cuál sería, pues, una definición que pudiera concitar un mayor consenso? Cuando decimos corrupción, viene a nuestra cabeza la imagen de alguien que es ventajoso, aprovechado, "que se comporta de una manera que socava y viola los principios de su Constitución o de sus tradiciones de derecho consuetudinario" (Chipkin, 2013: 213); que realiza "acciones que no necesariamente son buenas, que son dudosas, el resultado de la influencia del enojo, la ansiedad y la avaricia" (Birch, Allen \& Sarmiento- 
Mirwaldt, 2017: 1); que no se apega a "las normas, [le] falta habilidad para distinguir entre los fines organizacionales y los personales" (Levine, 2005: 723); “abusa o hace mal uso de recursos" (Aguilera \& Vadera, 2008); puede llegar a volverse indeseable y destructivo de las relaciones en la sociedad, más aún, un "enemigo de la humanidad" (Pertiwi, 2018: 1).

Más allá de los matices, el denominador común en la discusión es su etiqueta negativa. La acción corrupta es algo que está mal, es "un alejamiento de la norma moral" (Moore, 2007), "una desviación de los comportamientos y normas establecidas" (Voliotis, 2015: 148), más aún "un ataque a las normas" (Levine, 2005). Visto de esta manera, el término está cargado de moralidad (De Graaf, 2007) debido a que se asocia a la impureza moral contenida en ciertas acciones (Holmes, 2015), y no solamente al "abuso del poder encomendado para obtener un beneficio propio", tal como lo han venido popularizando Transparencia Internacional y el Banco Mundial desde hace más de una década, y que consideramos tiene un claro trasfondo smithiano no declarado por dichos organismos.

La noción aparece abordada en la segunda parte del análisis que Adam Smith realiza en la La Riqueza de las Naciones en torno a los deberes del soberano $^{6}$, haciendo alusión a la manera en que administraban la justicia los gobiernos bárbaros de Europa fundados después de la caída del imperio romano. Ahí introduce el concepto del siguiente modo:

El sistema de convertir la administración de justicia en una fuente de ingresos no puede por menos producir ciertos intolerables abusos. La persona que demanda justicia con un rico presente por delante, es probable que consiga algo más que justicia, y menos quien no puede ofrecer un don tan cuantioso. La justicia a veces también se difiere, para que el regalo se repita. La multa que se exige del acusado es a veces una razón más que suficiente para hallarle culpable aun cuando en realidad no lo sea. Que estos abusos no constituían una excepción, es algo de que ofrece testimonio la antigua historia de casi todos los países europeos (Smith, 2004b: 634).

Esta aproximación Smith la comienza en La teoría de los sentimientos morales explicitándola a través de la historia de "el hijo del hombre pobre", y donde encuentra el germen de la corrupción: la tensión que existe entre los binomios posición económica-poder y cuna-pobreza ${ }^{7}$.

$6 \quad$ El segundo de los cuatro deberes decía: "Proteger, hasta donde sea posible, a los miembros de la sociedad contra las injusticias y opresiones de cualquier otro componente de ella" (Smith, 2004b: 628).

7 La historia del hijo pobre, más allá de la detallada crónica respecto a la vida que lleva el pobre que sirve al rico, en ella, Smith hace una alusión importante a la manera en que nuestros sentimientos morales pueden corromperse por "la costumbre a admirar [y desear lo que poseen] los ricos y poderosos” (Smith, 2004a: 93). 
A decir de nuestro autor, "el nacimiento y la fortuna son evidentemente las dos circunstancias principales en que se asienta la superioridad de un hombre sobre otro. Son las razones fundamentales de la distinción personal y, por consiguiente, la causa más importante que establece entre ellos, de una manera que pudiéramos llamar natural, subordinación y disciplina" (Smith, 2004b: 632). En ese entonces, tal y como continúa hasta nuestros días, quien no poseía los medios para entregar un don que el soberano considerara cuantioso, quedaría fuera de la mano de la justicia.

El fin del sistema de "dádiva" u obsequio al soberano se dio con la llegada de los jueces y a decir de nuestro autor, fue uno de los frenos a la corrupción, siendo los pobres los más beneficiados con el cambio de sistema.

Acotada la noción, procederemos a analizar algunas de sus causas y efectos con el propósito de indagar la conexión de las primeras con la aporofobia e insensibilidad moral descritas en el epígrafe anterior y, de esta manera, identificar la potencialidad que tiene la simpatía smithiana para desactivarlas.

\section{UNA VÍA PARA ENTENDER LAS CAUSAS Y EFECTOS DE LA CORRUPCIÓN}

Gjalt De Graaf realiza una clasificación de seis teorías que explican la causalidad de la corrupción: la elección pública, la manzana mala, la cultura organizacional, el choque entre valores morales, el ethos de la administración pública y la correlación.

Con relación a la "teoría de la elección pública", De Graaf señala que la cadena causal que detona el acto corrupto se encuentra en "un individuo (usualmente hombre) que representa a una persona, racionalmente calculadora, que decide volverse corrupta en el momento que las ventajas esperadas pesan más que las desventajas. [...] si los beneficios de la corrupción, menos la probabilidad de ser atrapado, multiplicado por las penalidades, son mayores que los beneficios de no ser atrapado, entonces un individuo elegirá racionalmente ser corrupto" (De Graaf, 2007: 47). La razón para corromperse es simple: los beneficios son mayores que los riesgos potenciales. Lo más sorprendente del hecho es que "el agente racionaliza y legitima dicho comportamiento, sin considerarlo como corrupto (De Graaf, 2007: 50), mucho menos los efectos sociales que dicho acto genera. Este último aspecto, consideramos, mantiene alguna relación con la ceguera moral referida por Bauman. No obstante, creemos, la "asepsia lógica" del planteamiento se enturbia ante una pregunta como esta: ¿si el cálculo para corromperse resulta a favor, significa que quienes deciden no corromperse no son capaces de calcular? 
El segundo conjunto de teorías, quizá el menos popular de los seis, se define como "la manzana mala". Aquí la corrupción se origina en el nivel individual, y su cadena causal se encuentra "en un mal carácter que genera actos corruptos; la raíz de la corrupción se encuentra en un defecto del carácter y una predisposición a actuar de manera criminal" (De Graaf, 2007: 49). El problema añadido, es que cuando la causa reside en la debilidad moral del carácter, como dice Moisés Naím en Corruption Eruption (1995), fortalecer los valores morales resulta un antídoto difícil de llevar al diseño de una política eficaz dirigida al combate de la corrupción. Los tropiezos y poca efectividad que ha tenido la educación valoral promovida desde las aulas, en cierta forma, podrían darle la razón a Naim, de ahí que veamos como una posibilidad razonable explorar la potencialidad de la simpatía como criterio normativo para el diseño de ciertas políticas públicas, específicamente las que están asociadas al combate de la corrupción. Dicho en otras palabras, el diseñador de la política no tendría que ser un "dechado de virtudes", pero la política pública sí debería haberse diseñado desde el lugar de aquellos a los que se dirige.

El tercer grupo de teorías es el de "la cultura organizacional", el cual se ubica en un nivel causal meso, es decir, en el plano de la organización, y no propiamente en el comportamiento individual. Aquí, la corrupción surge como parte de un efecto "contagio" que proviene de "una cultura, un tipo de cultura que provoca un cierto estado mental, y ese estado mental conduce hacia el comportamiento corrupto" (De Graaf, 2007: 52). A decir de Peter Levine, en el contexto de las organizaciones empresariales, "este estado mental proviene de la avaricia, la cual, no solo lleva al quiebre de las actuaciones éticas, sino al cambio de rumbo de algunas acciones con las que la organización decía estar comprometida (Levine, 2005: 736) o, incluso, como señala Seraphim Volitis, a abrazar una serie de valores y prácticas que hacen de la organización un ente antisocial (Voliotis, 2015), corrompido (Moore, 2007) y destructivo (Pertiwi, 2018).

A diferencia de la "elección pública" o la "manzana mala", debido a sus efectos "contagiosos", esta causa trasciende al individualismo metodológico que mueve al cálculo egoísta, debido a que las personas son contagiadas por la cultura organizacional, espacio donde cualquier persona "corre el enorme riesgo de volverse corrupto" (De Graaf, 2007: 52). Una vez más la simpatía podría servir como una vía para "re-sensibilizar" a quien ha perdido su capacidad para entender los efectos que causa el acto corrupto en la vida de los demás.

El cuarto conjunto teórico es el del "choque entre valores morales". Aquí la corrupción se deriva de una cadena causal macro, "donde los valores que vive una sociedad directamente influencian los valores y normas 
individuales. Esos valores y normas influencian el comportamiento individual de oficiales, haciéndolos corruptos" (De Graaf, 2007: 52).

Probablemente suene una exageración afirmar que exista "el país de las mentiras" (De la Isla, 2017), sin embargo, en algunos países resulta muy delgada la línea que separa la acción virtuosa de la corrupta. Mientras que en China no solo es normal, sino deseable, que un negocio se abra y cierre intercambiando algunos regalos, esa misma práctica resulta satanizada en otro país. Un mismo empresario puede hacer un lindo obsequio en el contexto asiático y abstenerse de hacerlo en una reunión de negocios en $\mathrm{Ca}$ nadá. Con todo, los valores que se viven en el plano macro de una sociedad permean los idearios y prácticas, tanto de las organizaciones como de los individuos que las conforman. Este ejemplo nos permite comprender con más claridad porqué la noción de corrupción se vuelve hasta cierto punto elusiva al momento de querer encerrarla en una definición que dé cuenta de toda la complejidad del fenómeno.

El quinto grupo es "el ethos de la administración pública”, y proviene de una relación causal societal, y que, por su configuración y forma de influencia, se encuentra muy próximo al de "la cultura organizacional", pero se separa de ésta en el hecho de que "hay una mayor preocupación sobre cómo la cultura que existe al interior de la dirección pública y la sociedad en general [...] se presentan como macro factores que influyen en el trabajo de las organizaciones y de los individuos en particular" (De Graaf, 2007: 56). Sin ser un caso exclusivo, este tipo de teoría explica perfectamente una práctica que se presenta en México que ha sido denunciada en muchas ocasiones por la organización civil Mexicanos Unidos contra la Corrupción y la Impunidad: la única manera que una empresa o profesionista independiente tiene de llevar a cabo algún proyecto contemplado en una licitación pública es siendo parte de las reglas del juego de la corupción; del valor total de la obra una parte deberá ser destinada al rubro "gastos sin comprobar", los cuales, muchas veces representan hasta el 20 por ciento del valor total de la inversión. Dicha forma de operar atenta claramente contra los valores que configuran el ethos moral no solo de las empresas, sino de cualquier administración pública: "bien común, custodia, integridad, mérito, transparencia, responsabilidad y verdad" (De Graaf, 2007: 57).

Sobre este último valdría la pena pensar si dicho ethos, además de los valores que encarna, debería tener en cuenta la capacidad de simpatizar de los funcionarios de la administración pública con los receptores de sus servicios. Exigir secreta o abiertamente el pago de un 20 por ciento del valor total de la obra, no solo pone en riesgo la viabilidad económica de la empresa, sino que deja a la sociedad sin el bien o servicio ofrecido por ella. 
Por último, "la correlación de teorías" se presenta como un conglomerado teórico que defiende la multicausalidad implicada en el fenómeno de la corrupción, ya que como bien define Gerald Caiden:

Así como con frecuencia ocurre en la ciencia, cuanta más atención recibe un tema, más complicado se vuelve. La corrupción deviene en muchas formas, por ello es fácil caer en la generalización ... Hay un alto-nivel y un bajo-nivel de corrupción, y está la predominantemente política y la predominantemente burocrática. Están la endémica, la penetrante, la aislada, y las menos frecuentes. Están las complejas redes que se fortalecen y las aisladas, simples, directas y bilaterales con efectos contradictorios. Está la amplia, disruptiva y la pequeña, la trivial. El intercambio corrupto puede ser grande o pequeño, raro o frecuente, abierto o cerrado, entre iguales y desiguales; puede ser tangible o no tangible, durable o no durable, rutinario o extraordinario. Los canales pueden ser legítimos o no legítimos. Sin embargo, la confusión no invalida ciertas generalizaciones universales... (Caiden, 2001: 78).

Consciente de la diversidad de formas y relaciones que detonan y tejen la corrupción, este grupo teórico trata de analizar sus causas mediante una "correlación que no comienza con una explicación teorética implícita o explícita, sino de factores específicos [...] de variables que pueden ser consideradas en todas sus posibilidades a todos los niveles: individual, organizacional y societal" (De Graaf, 2007: 59).

Este tipo de estudios, similar a lo que sucede con este artículo, trata de entender, más que de definir o explicar-lo-que-es, la manera en que la corrupción distorsiona la competencia leal, perjudica el acceso equitativo a los bienes y servicios públicos, socava la legitimidad del gobierno (Gorsira, Denkers \& Huisman, 2018) e incluso, siendo esto quizá la parte más perversa, impide a quienes manejan los recursos públicos ponerse en el lugar de las personas que viven avergonzadas por su condición de pobreza (Smith, 2004b: 123).

Sobre las posibilidades que tiene la simpatía smithiana para desactivar algunos de los mecanismos que activan la aporofobia y ceguera moral referidas por Cortina y Bauman, tratará el siguiente epígrafe.

\section{LA SIMPATÍA SMITHIANA}

En La teoría de los sentimientos morales, Adam Smith afirma que la simpatía, "en su sentido más propio y original, denota la compañía de sentimientos con el padecer y no con el placer de los demás" (Smith, 2004a: 113). Sin embargo, si damos un paso más allá de esta definición, como dice D. D. Raphael, encontraremos que Adam Smith también utilizaba la noción para explicar dos diferentes clases de juicio moral: "el primero es un juicio 
acerca de la 'propiedad de la acción’, que la enjuicia como correcta o incorrecta. El segundo, es el juicio sobre el mérito o el demérito de la acción; el juicio sobre lo que merece el orgullo o la vergüenza, la recompensa o el castigo" (Raphael, 1985: 29-30).

Esta primera aproximación nos permite entender la simpatía como el fundamento del juicio sobre la propiedad y la justicia, la incorrección o la injusticia de una acción, la fuente primaria que determina cuándo una acción propia o ajena es meritoria y, por tanto, objeto de recompensa o, por el contrario, indigna o es objeto de castigo.

Sin embargo, recuperar el sentido de la simpatía defendida por Adam Smith, no responde a la pregunta ¿qué es simpatizar?, de ahí que convendría valernos de un ejercicio imaginativo para dar cuenta de tal propósito.

Ubiquémonos en una situación donde somos espectadores de una escena donde una persona, ahogada por el llanto, yace postrada en el suelo. Aparentemente, el motivo de su desconsuelo es que la casa donde ha vivido toda su vida quedó reducida a cenizas debido a una falla eléctrica. Siendo espectadores de la escena, ¿cómo enjuiciar la intensidad del llanto y dolor expresado por esa persona? ¿Qué posibilidades ofrece el principio de la simpatía para ello?

Resulta obvio que siendo solo espectadores no podemos sentir lo que siente esa persona, ya que no somos los actores de tales sentimientos. Hasta este punto, los sentimientos que vamos a enjuiciar sólo podemos captarlos desde lo que nuestros sentidos nos informan (Hume, 1988) ${ }^{8}$. Son nuestros sentidos la fuente informacional desde donde determinamos si la intensidad del llanto, los gritos o aspavientos del actor se ajustan a las causas que los originaron. Sin embargo, ¿cómo podemos tener certeza de que éstos no nos engañan?

Smith nos dirá que cuando somos meros espectadores de un sentimiento ajeno, no podemos "hacernos ninguna idea de la manera en que [esa persona] se ve afectada, salvo que pensemos cómo nos sentiríamos nosotros en la misma situación” (Smith, 2004a: 49). Así, por más próximos que nos encontremos del calor de las cenizas de lo que fuera un hogar, requerimos "dar un paso más" para poder comprender y entrar en el dolor de la otra persona, para así, sin dejar de ser nosotros mismos, sentirlo, entenderlo, vivirlo.

A decir de Smith, el medio que subsana la insuficiencia natural de nuestros sentidos es la imaginación, la cual se presenta como el primer gran componente del proceso simpatizador. Gracias a la imaginación po-

Para profundizar sobre la manera en que David Hume entendía el proceso bajo el cual se produce la simpatía, y Adam Smith lo continúa, revisar Carrasco (2018). 
demos hacernos una idea mucho más viva, próxima y precisa de los sentimientos, especialmente de las aflicciones, de quienes nos rodean. De igual forma, la imaginación nos permite descubrir la intensidad que imprimieron las causas de dichos sentimientos y "concebir que padecemos los mismos tormentos, entrar por así decirlo en su cuerpo y llegar a ser en alguna medida una misma persona con él y formarnos así una idea de sus sensaciones, e incluso sentir algo parecido, aunque con una intensidad menor" (Smith, 2004a: 50).

De este modo, el primer paso para poder enjuiciar la situación de otra persona sería dejar nuestra posición para entrar en la de ella. Una vez que nos hemos puesto en los zapatos del actor', una vez que por un momento nos hemos vuelto él, estaremos en condiciones de poder enjuiciar de un modo más objetivo la corrección o incorrección de sus sentimientos. Hacer este cambio imaginario de roles, nos posibilita enjuiciar los sentimientos ajenos desde la óptica de un espectador no implicado, ya que el juicio ahora se desarrollará a partir de la posición del actor del sentimiento ${ }^{10}$.

Aunque el cambio de posiciones solo es imaginario, como señala James Otteson, ello no elimina el hecho de que la simpatía surja de la correspondencia, de la exacta coincidencia, entre los motivos y sentimientos del actor, con los que imagina y ahora siente el espectador (Otteson, 2002). Así, la fuente de conmiseración y aprobación del espectador respecto aquello que siente el actor del sentimiento, surgirá de ese momento donde el primero ha hecho suyos los sentimientos del que sufre. En este sentido, tal como sugiere Alexander Broadie, "para Smith, la simpatía no puede ser separada del espectador, porque son los espectadores quienes simpatizan" (Broadie, 2006: 158).

Considerado lo hasta ahora dicho, la pregunta ¿qué es simpatizar?, se respondería del siguiente modo: entendemos por simpatizar la correspondencia que existe entre los sentimientos de un agente y los de quien es el espectador de los mismos, una vez que éste, poniéndose en el lugar del actor, ha considerado que las causas que originaron sus sentimientos son adecuadas a la intensidad, efecto y consecuencias con que se expresan.

Volviendo a nuestro ejemplo, el llanto, la rabia manifiesta, las palabras altisonantes al viento o los puntapiés dados a los restos calcinados del que fuera un hogar, pueden ser enjuiciados por el espectador como una reacción y consecuencia apropiada por parte del agente, ya que, ahora habiendo logrado simpatizar con éste, se encuentra en condiciones de comprender que si él se viera en una situación similar podría actuar del mismo

9 Para referirse a esta persona, Smith también emplea las palabras: paciente, agente, doliente, afectado.

10 Y no solo el sentimiento, sino desde lo que genera la situación que le aqueja. 
modo. En tales condiciones, los sentimientos externalizados por el agente, dirá Smith, aparecerían como correctos, apropiados y ajustados a sus causas.

4. SIMPATIZAR CON EL DOLOR PROFUNDO, CONCRETAMENTE EL QUE GENERA LA POBREZA

En el planteamiento smithiano, la simpatía hacia la aflicción posee algunos niveles. Dicho en sus propios términos, "las pequeñas molestias no promueven simpatía alguna, pero un profundo pesar, la anima en alto grado" (Smith, 2004a: 107).

Cuando la desgracia es grave, como por ejemplo la vivida por los pobres alimentarios que se quedaron sin el apoyo social debido al fraude orquestado a través de "la estafa maestra" referida en el primer epígrafe, "nuestra simpatía con su profunda desdicha es muy intensa y sincera" (Smith, 2004a: 109). Más aún, "La voz quejumbrosa de la miseria, si es oída a la distancia, no nos permitirá ser indiferentes acerca de la persona de la cual proviene. Tan pronto impacte sobre nuestros oídos, nos hace interesarnos en sus avatares y, si continúa, nos fuerza casi involuntariamente a acudir en su ayuda" (Smith, 2004a: 98). Consideramos que hay tres argumentos que subyacen a este último planteamiento.

Para Smith, la pobreza y las consecuencias que ésta genera, resultan ser una de las más graves desgracias a las que se puede enfrentar una persona ${ }^{11}$. Por tanto, las condiciones bajo las cuales transcurre la vida del pobre a nadie deberían resultar indiferentes, siendo éstas el justo motivo por el que puede despertarse en nosotros la mayor y más profunda simpatía.

11 Dado que Smith nunca consideró la complejidad de la pobreza en una definición cerrada, si reconstruimos las alusiones que él hace al fenómeno tendríamos que pobre es quien no goza ni tiene oportunidad de disfrutar de tres tipos de condiciones básicas en la vida de todo hombre: materiales, sociales y emocionales. Una persona que poseyera estas condiciones estaba ante la puerta de entrada del "ser observada, atendida, considerada con simpatía, complacencia y la aprobación ajena" (Smith, 2004a: 123). En el planteamiento smithiano alguien es absolutamente pobre cuando, además de la precariedad material en la que transcurre su vida, ha sido privado de algo fundamental para la realización y humanización de la vida en sociedad: la consideración simpatética, respeto y aprobación de quienes le rodean. Es aquí donde la pobreza trasciende el espacio económico y se encarna en el moral, ya que "el pobre está avergonzado de su pobreza. Siente que o bien lo excluye de la atención de la gente, o bien, si le prestan alguna atención, tienen escasa conmiseración ante la miseria y el infortunio que padece. En ambos casos resulta humillado, porque si bien el ser pasado por alto y el ser desaprobado son dos cosas diferentes, como la oscuridad nos cierra el paso a la luz del honor y la aprobación, el percibir que nadie repara en nosotros necesariamente frustra la esperanza más grata y abate el deseo más ardiente de la naturaleza humana" (Smith, 2004a: 123). 
La segunda razón por la que simpatizamos con el pesar del desdichado, tiene su origen en la definición más conocida ofrecida por Smith: "la palabra simpatía, en su sentido más propio y original, denota nuestra compañía de sentimientos con el padecer y no con el placer de los demás. [...] Ante todo, en algún sentido es más universal nuestra simpatía con el dolor que con el regocijo" (Smith, 2004a: 113).

La tercera razón tiene un trasunto estoico, que Smith entendió como "divina elegancia". A decir de él, debido a que estamos preparados para cargar un dolor similar al que somos capaces de aliviar en los demás, cuando vemos que la persona lo soporta con magnanimidad, tal como lo hacen muchas personas que viven en pobreza extrema o en pobreza patrimonial $^{12}$, nuestra simpatía brota de manera instantánea para poner en marcha su capacidad restauradora y vinculante.

Lo dicho hasta el momento nos permite adelantar una suerte de conclusión: nuestra capacidad para simpatizar con el dolor ajeno, especialmente el profundo, hacen del recurso de la simpatía una vía para desactivar los mecanismos que, en el plano fisiológico, dirá Bauman, activan nuestra insensibilidad moral ante la realidad que viven los demás, especialmente los pobres, esos que, como refiere Adela Cortina, en una sociedad de mercado aparentemente no tienen nada que ofrecer.

\section{EL APORTE SOCIAL DE LA SIMPATÍA EN LA LUCHA CONTRA LA CORRUP- CIÓN}

En La Riqueza de la Naciones, Adam Smith desarrolla una tesis que vertebra su planteamiento económico-político: "ninguna sociedad puede ser floreciente y feliz si la mayor parte de sus miembros son miserables y pobres" (Smith, 2004b: 77). Más allá de que la tesis sirve como contrargumento para replicar a quienes consideran a Smith como un defensor acérrimo del liberalismo económico en su versión más ortodoxa, representa el contenido del ideal normativo que pudiera orientar tanto el diseño institucional (el puerto de llegada societal smithiano) como el tono de nuestras interacciones cotidianas.

Estamos conscientes que, seguramente, son más los aportes que la simpatía puede tener en la lucha contra la corrupción, sin embargo, en el contexto latinoamericano, podemos encontrar, al menos, cinco:

\footnotetext{
12 Jon Elster (1988) señala que dicha capacidad reside en la activación de la preferencia adaptativa que permite a las personas superar algunos conflictos cognitivos que, en determinado momento, les impediría llegar a tener una vida con sentido.
} 
1. La simpatía sirve como una forma de cohesivo social que potencia la hermandad. Cuando el mecanismo de la imaginación nos permite entrar en la situación del que sufre, como señala Smith, éste "experimenta la reducción inmediata de su dolor", despertando en él un sentimiento de gratitud hacia quien, siendo solo un espectador, hizo suyo un dolor que en sentido estricto no le correspondía.

Entendida de esta manera, la simpatía funciona como una suerte de cohesivo social que hermana, que aproxima, que une a quien nació arropado por la fortuna de cuna con quien no la tuvo.

2. La simpatía sirve como un criterio para evaluar el impacto bumano que trae consigo romper una norma asociada al actuar integro (bonesto). Como señalamos líneas atrás, la simpatía smithiana nos permite juzgar la corrección o incorrección de los motivos que detonaron un sentimiento. Sin embargo, si profundizamos un poco más en la potencialidad contenida en la noción, descubriremos que ésta también permite enjuiciar el nivel de afectación humana que trae consigo el quebrantamiento de una norma vinculada al comportamiento honesto. Pensar tales efectos en términos de una racionalidad simpatética, abre una ventana de posibilidades para ir más allá del cálculo estadístico, el recuento de daños colaterales y las colas de Pareto, entre otras.

3. La simpatía puede ser una de las vías para concientizar a quienes los manejan, sobre la necesidad de reorientar recursos públicos hacia los que más sufren. Quien mediante un proceso simpatético puede tomar el sitio del excluido, del marginado, del invisibilizado por causa de su condición de pobreza, además de permitirle experimentar "en carne propia" tal condición, podrá comprender la circunstancia puntual del excluido y el impacto que trae a su vida el conjunto de derechos que, por la vía legal o por medio de un acto corrupto, le han sido negados. De igual forma, este imaginario cambio de posiciones, podría darle mayor claridad a quien administra los recursos públicos respecto a qué es lo que necesita una persona para que los males que generan su dolor o condición puedan ser atendidos.

4. Integrar a quienes no han sido considerados miembros valiosos de una comunidad. En el momento que somos capaces de ponernos en los zapatos del "hombre más gris de la sociedad", nos daremos cuenta que su apagado color, en buena medida, encuentra su causa en el rol que dicha persona ha tenido en la sociedad, papel que, en no pocas ocasiones, depende de los recursos que provee la fortuna de cuna.

En ese sentido, como dice Lisa Hill, una "función o propósito de nuestra capacidad para simpatizar es alcanzar la 'armonía' social 
en sociedades de masa" y, por otro lado, nos posibilita construir una personalidad más comprometida consigo y el entorno (Hill, 2017: 14); una personalidad "más sana" debido a que reconoce su valía y papel que juega en la autodefinición de sus semejantes, sobre todo, de aquellos que precisan de la consideración, respeto y de una mirada que los vea con el mismo aprecio y consideración que tiene para sí.

5. Una vía para que la prosperidad material sea distribuida de una manera más justa. La simpatía smithiana no invoca esa benevolencia divina que nunca espera nada a cambio (Smith, 2004: 265-342). La simpatía promovida por Smith, como dijimos atrás, trata de conciliar en una persona sus deseos de bienestar individual, con la más profunda y sentida consideración por el dolor y destino de quienes le rodean, en especial, los que más sufren en una sociedad, es decir, aquellos que viven en condiciones de miseria y pobreza.

\section{CONCLUSIONES}

La corrupción, como concepto, es un término elusivo. Su multicausalidad, tipos de actores implicados, sectores donde surge y encarna, mecanismos mediante los que opera, así como algunos de los impactos que genera, hacen difícil acotarla en un concepto cerrado. Con todo, hay una constante que sirve para definirla y comprenderla: su trasfondo moral.

Visibilizar la raigambre smithiana de la idea de corrupción que ha venido siendo difundida por instituciones como el Banco Mundial o Transparencia Internacional, no sólo permitiría dar crédito a quien pudiera ser considerado su precursor, sino que posibilitaría recontextualizarla y, con ello, ampliar su potencialidad, su fuerza moral, especialmente, en países donde la mayoría de sus habitantes viven "en condiciones de miseria y pobreza".

Los casos de corrupción referidos ("Panamá Papers", "Lava Jato", "Los cuadernos" y "La estafa maestra"), además de permitirnos comprender la gravedad empírica de sus impactos, dejan al descubierto la aporofobia y ceguera moral que los motivó, donde la simpatía smitihiana, entendida como competencia moral (desarrollable, incluso, desde las aulas), tiene potencialidad para atenuarlas, e incluso, detenerlas.

Consideramos que en trabajos futuros, si continuamos indagando sobre el "poder restaurador" de la simpatía smithiana, los resultados de éstos podrían ser extrapolados al diseño institucional de estrategias y políticas públicas dirigidas al combate de la corrupción, e incluso a otras que se dirigen a la lucha contra la pobreza. 
Pensarlas, diseñarlas y habilitarlas desde una racionalidad simpatética podría ayudar a que sus beneficiarios reciban lo que en justicia les corresponde; tal como debiera suceder en una sociedad donde existe claridad sobre el quiebre moral que existe cuando la mayoría de sus miembros viven en condiciones de miseria y pobreza.

\section{REFERENCIAS}

Aguilera, R. \& Vadera, A. (2008). The Dark Side of Authority: Antecedents, Mechanisms and Outcomes of Organizational Corruption. Journal of Business Ethics, 77(4), 431-449.

Animal Político (2017). “¿Dónde quedó el dinero de los más pobres?”, Animal Politico, disponible en https://www.animalpolitico.com/estafa-maestra/sedesol-donde-quedo-dinero-pobres.html

Appiah, A. (2007). Cosmopolitisimo. La ética en un mundo de extraños. Buenos Aires: Katz.

Ayala, P. (2016). Los "Panamá Papers". Parte I. El Noroeste. Recuperado el 23 de noviembre en: https://www.noroeste.com.mx/publicaciones/opinion/plos-lsquopanamaacute-papersrsquo-parte-ip-94131

Bauman, Z. \& Donskis, L. (2015). Ceguera Moral. La pérdida de sensibilidad en la modernidad líquida. Paidós: México.

Birch, S., Allen, N. \& Sarmiento-Mirwaldt, K. (2017). Anger, Anxiety and Corruption Perceptions: Evidence from France. Political Studies, 65(4), 893-911.

Broadie, A. (2006). Sympathy and the Impartial Spectator. En K. Haakonssen, The Cambridge Companion to Adam Smith. Cambridge: Cambridge University Press.

Cabot, D. (2018). Los cuadernos de las coimas: la enigmática caja que escondía una bitácora de la corrupción K. En La Nación, disponible en https://www.lanacion.com.ar/2158181-la-enigmatica-caja-de-cuadernosque-escondia-una-bitacora-de-la-corrupcion-de-la-era-k

Caiden, G. (2001). Corruption and Governance. En G. Caiden, O. Dwivedi \& J. Jabbra (eds.), Where Corruption Lives (pp. 15-37). Bloomfield: Kumarian Press.

Cardona, L., Ortiz, H. y Vázquez, L. (2018). Violación de derechos humanos en México: Un costo poco advertido de la corrupción. Politica y Gobierno, 25(1), 153-184.

Carrasco, M. (2018). Sentimentalismo escocés: Hume y Smith contra el egoísmo moral. Veritas, (4), 55-74.

Chipkin, I. (2013). Whither the State? Corruption, Institutions and State Building in South Africa. Politikon, 40(2), 211-231.

Cortina, A. (2000). La ética de la sociedad civil. Madrid: Alauda.

Cortina, A. (2013). ¿Para qué sirve realmente la ética? México: Paidós.

Cortina, A. (2017). Aporofobia, el rechazo al pobre. Un desafio para la democracia. Madrid: Paidós.

De Graaf, G. (2007). Causes of Corruption: Towards a Contextual Theory of Corruption. Public Administration Quarterly, 31(1/2), 39-86. 
De la Isla, C. (2017). La transparencia o “por un México sin mentiras". Estudios. Filosofía, Historia, Letras, 15(122), 205-209.

Elster, J. (1988). Uvas amargas: sobre la subversión de la racionalidad. Barcelona: Edicions 62.

Gorsira, M., Denkers, A., \& Huisman, W. (2018). Both Sides of the Coin: Motives for Corruption Among Public Officials and Business Employees. Journal of Business Ethics, 151(1), 179-194.

Hill, L. (2017). The poor man's son and the corruption of our moral sentiments: comerce, Virtue and happiness in Adam Smith. The Journal of Scottish Philosophy, 15(1), 9-25.

Holmes, L. (2015). Corruption: A Very Short Introduction. Oxford: Oxford University Press.

Hume, D. (1988). Disertación sobre las pasiones y otros ensayos morales. Barcelona: Anthropos.

Klempner, G. (2017). Ethical Dilemmas: A primer for decision makers. Kindle edition. Levine, D. P. (2005). The corrupt organization. Human Relations, 58(6), 723-740.

Moore, C. (2007). Moral Disengagement in Processes of Organizational Corruption. Journal of Business Ethics, 80(1), 129-139.

Myers, A. \& Rouzaud, D. (2016). El Sistema Nacional Anticorrupción. Estudios, 14(119), 137-159.

Naím, M. (1995). Corruption Eruption. Disponible en https://carnegieendowment.org/1995/06/01/corruption-eruption-pub-648

Nietzsche, F. (2015). Humano demasiado humano. Madrid: Edaf.

Otteson, J. (2002). Adam Smith's Marketplace of Life. Cambridge: Cambridge University Press.

Pertiwi, K. (2018). Contextualizing Corruption: A Cross-Disciplinary Approach to Studying Corruption in Organizations. Admistrative Sciences, 8(12), 1-19.

Raphael, D. D. (1985). Adam Smith. Oxford: Oxford University Press.

Smith, A. (2004a). La teoría de los sentimientos morales. Madrid: Alianza.

Smith, A. (2004b). La riqueza de las naciones. México: FCE.

Voliotis, S. (2015). Establishing the Normative Standars that Determine Deviance in Organizational Corruption: Is Corruption Within Organizations Antisocial or Unethical? Journal of Business Ethics, 140(1), 147-160.

Sumario: Introducción; 1. La corrupción y su entramado moral; 2. Una vía para entender las causas y efectos de la corrupción; 3. La simpatía smithiana; 4. Simpatizar con el dolor profundo, concretamente el que genera la pobreza; 5. El aporte social de la simpatía en la lucha contra la corrupción; Conclusiones; Referencias. 